\title{
MODALIZADORES: A NEGOCIAÇÃO EM ARTIGO DE OPINIÃO
}

\author{
Alcione Tereza Corbari ${ }^{*}$ \\ Universidade Estadual do Oeste do Paraná \\ Centro de Educação, Comunicação e Artes \\ Cascavel, PR, Brasil
}

\begin{abstract}
Resumo: Este artigo apresenta resultados parciais de tese de doutoramento que teve por objetivo investigar o uso de estratégias de modalização linguística, considerando o papel dos modalizadores no processo de negociação demarcada pelo relacionamento que o produtor estabelece com o conteúdo do texto e com o interlocutor. Tomam-se, para análise, modalizadores dos eixos epistêmico e deôntico ambientados em parágrafos de artigos de opinião produzidos por alunos do $3^{o}$ ano do Ensino Médio de uma escola pública de Cascavel/PR. A pesquisa, de cunho preponderantemente qualitativo, adota como procedimento metodológico a análise textual qualitativa, e considera uma perspectiva descritivo-interpretativa. O estudo é sustentado em pressupostos teóricos que preconizam a análise de textos reais e que permitem considerar expedientes linguísticos específicos, tendo em conta as condições enunciativas envolvidas na produção do texto. Observou-se que os alunos recorrem a estratégias de relacionamento face ao próprio texto e ao interlocutor, que foram congregadas em duas categorias: negociação enfática e negociação atenuada, que envolvem, respectivamente, os atos ilocutórios de asserção forte e de asserção fraca.
\end{abstract}

Palavras-chave: Modalizador. Negociação. Artigo de Opinião. Ensino Médio.

1 CONTEXTUALIZANDO A PESQUISA

Este artigo apresenta resultados parciais de tese intitulada Elementos modalizadores como estratégia de negociação em textos opinativos produzidos por alunos de Ensino Médio $^{1}$, defendida em 2013 na Universidade Federal da Bahia. A pesquisa é guiada pelo objetivo de investigar o uso da modalização, tomada como estratégia de argumentação, considerando o papel dos modalizadores no processo de negociação estabelecido entre os interlocutores.

O corpus de análise é formado por parágrafos retirados de artigos de opinião produzidos por alunos do Ensino Médio de uma escola pública de Cascavel/PR. Os textos constituem a terceira versão de uma produção motivada, orientada e acompanhada em sala de aula. Na seleção dos parágrafos, observou-se a presença de elementos modalizadores stricto sensu dos eixos epistêmico e deôntico. Considera-se o parágrafo uma das partes do texto que contém estratégias de negociação, que podem ser promovidas por recursos linguísticos diversos, mas que se explicitam de forma mais evidente nos modalizadores em termos de posicionamento do produtor em relação ao texto e ao interlocutor.

\footnotetext{
* Doutora em Letras e Linguística pela Universidade Federal da Bahia. Professora Adjunta do Curso de Letras na Universidade Estadual do Oeste do Paraná, campus de Cascavel. E-mail: alcione_corbari@hotmail.com.

1 A pesquisa foi orientada pela professora doutora Iracema Luiza de Souza (Ufba) e coorientada pela professora doutora Aparecida Feola Sella (Unioeste).
} 
Vale observar que os textos de onde foram retirados os parágrafos são aqui referenciados como artigo de opinião, mas que precisam ser considerados a partir das condições de produção, circulação e recepção real do gênero. As características sociocomunicativas e funcionais reais do artigo de opinião são diversas nesse contexto em comparação com aquele que circula na esfera jornalística. Verifica-se que a forma como os alunos propõem relacionamento com o conteúdo do texto e com o interlocutor é bastante diversa daquela observada em artigos de opinião produzidos por articulistas, pois estes, em geral, relacionam recursos linguísticos e lidam com o contexto de enunciação de forma mais produtiva do que os alunos o fazem.

Ainda assim, uma análise geral do corpus permite observar que os alunos atualizam elementos modalizadores no texto como "tentativas" de uma interação exitosa, considerando as intenções envolvidas na interação e o interlocutor previsto. Nesse sentido, a interação com o corpus pauta-se no entendimento de que "um texto produzido por um aprendiz manifesta-se como produto de um sujeito que, a seu modo, através das diversas possibilidades e formas de linguagem, busca estabelecer um determinado tipo de relação com o interlocutor" (LEAL, 2008, p. 54). Considera-se, pois, o aluno como alguém que está se constituindo como sujeito da própria produção, para usar os termos empregados por Rocha (2008).

A pesquisa proposta (CORBARI, 2013) caracteriza-se como sendo fundamentalmente qualitativa, pois, embora envolva também dados quantitativos, estes são interpretados a partir de um olhar subjetivo. De qualquer maneira, neste artigo, os dados quantitativos não são considerados, haja vista que não são relevantes para a proposição das categorias apresentadas, que constituem o foco deste texto.

Partindo do paradigma interpretativista, o estudo adota como procedimento metodológico a análise textual qualitativa (MORAES, 2003; MORAES; GALIAZZI, 2006, 2007), considerando uma perspectiva descritivo-interpretativa, sustentado em revisão bibliográfica e centrado em métodos e procedimentos que visam a descrever e a interpretar o fenômeno do mundo em uma tentativa de compartilhar significados com outros (MOREIRA; CALEFFE, 2008), os quais são subjetivamente produzidos.

Considerando os procedimentos adotados por autores de artigos de opinião que circulam na esfera jornalística para provocar efeito persuasivo no leitor, observa-se (CORBARI, 2008; BESSA NEVES, 2006, entre outros) que, nesse gênero, os elementos modalizadores assumem papel importante no delineamento de ideias e opiniões, demarcadas pela forma como o produtor se relaciona com seu enunciado ${ }^{2}$ e com o interlocutor (CASTILHO; CASTILHO, 1992; KOCH, 2002, 2003b; NEVES, 1996, 2006; PARRET, 1988; MIRANDA, 2005).

Em outras palavras, toma-se dos autores consultados a ideia geral de que a modalização retrata pontos de vista e sinaliza o tipo de interlocução pretendida. Além do próprio produtor, que mobiliza estratégias linguísticas conformadas a seus objetivos, suas intenções, toma lugar importante, na produção do texto argumentativo, o interlocutor, entendido como participante ativo da interação, que, somado a outras condições de enunciação, como o projeto de dizer $(\mathrm{KOCH}, 2003 \mathrm{a})$ e o gênero escolhido para levá-lo a

\footnotetext{
${ }^{2}$ O termo 'enunciado’ é tomado neste estudo conforme o propõe Ducrot (1987).
} 
cabo, direciona a escolha do conteúdo e da forma de apresentá-lo, dinâmica que envolve a noção de negociação. Considerando o texto argumentativo, a negociação diz respeito à forma como o produtor relaciona recursos linguísticos para orientar a construção de sentido(s) e agir sobre o interlocutor segundo os intentos que motivam a interação proposta.

Motiva a pesquisa aqui parcialmente publicada a observação de que poucos estudos têm considerado textos produzidos por alunos, especialmente no que se refere a trabalhos que tomam como foco de análise a modalização linguística. Apesar de ser uma questão já bastante debatida do ponto de vista científico, a relação entre modalização e argumentação ainda é pouco explorada no que tange à produção do texto ambientada em sala de aula. Por isso, intenta-se colaborar com a prática do professor do ensino básico, que carece ainda de um olhar analítico-descritivo voltado para o texto do aluno com vista a compreender as manobras realizadas quando do uso de modalizadores.

No que tange aos pressupostos teóricos, este estudo não se filia a um único modelo teórico. Tomam-se como basilares teorias que preconizam a análise de textos reais e que permitem considerar expedientes linguísticos específicos tendo em conta as condições enunciativas envolvidas na produção do texto, como as intenções discursivas, o interlocutor previsto e o gênero escolhido para a realização dessas intenções, entre outros aspectos.

Considerando o interesse de estudar a modalização a partir de uma perspectiva semântico-discursivo-pragmática, Castilho e Castilho (1992), Neves (1996, 2006), Koch (2002, 2003b), Parret (1988), Vion (2004, 2005), Miranda (2005) e Borillo (1982) são referências que auxiliam nas análises propostas. À contribuição desses autores se somam os estudos sobre a noção de negociação apresentados por Golder (1996), Golder e Coirier (1994, 1996) e Petroni (2005); tal noção é interpretada com respaldo em Bakhtin (2002, 2003), especialmente no que tange ao processo dialógico estabelecido entre os sujeitos da interação viabilizada pelo texto, e em Hengeveld (1989). Também contribuem para a pesquisa os estudos de Marcuschi (2008), Dascal (1986), Koch (2003a), Koch e Fávero (1987) e Rodrigues (2001), entre outros.

\section{ARGUMENTAÇÃO E NEGOCIAÇÃO NO ARTIGO DE OPINIÃO}

A pesquisa se pauta no pressuposto de que todo uso da linguagem retrata uma atividade sociointerativa (BAKHTIN, 2002; MARCUSCHI, 2008) que reflete as condições sócio-históricas da comunidade linguística ao mesmo tempo em que é por elas guiada. Observa-se a língua, um fenômeno encorpado e não abstrato e autônomo (MARCUSCHI, 2008), em seu funcionamento social, cognitivo e histórico, considerando que o sentido se produz situadamente.

A produção textual, então, configura-se como uma atividade intersubjetiva, uma vez que é na interação produtor-texto-leitor, em dada situação de interação e sob dadas condições sócio-históricas, que o sentido é construído. Essa atividade é gerenciada em uma "contextualidade accional", conforme propõe Parret (1988), concretizada "pelo triângulo (locutor, destinatário, situação de troca) e pela dialética da intenção e do 
reconhecimento da intenção pelo canal de fragmentos lingüísticos cujo suporte é a situação de troca" (PARRET, 1988, p. 102). Pode-se dizer que, no centro desse triângulo, está o texto, que não existe sem as três partes que o fazem emergir e o sustentam como uma unidade coerente em determinada situação de interação.

O texto é estrategicamente organizado pelo produtor em conformidade com as intenções que movimentam a interação $(\mathrm{KOCH}, 2003 \mathrm{a})$, que motivam a busca por estratégias linguísticas diversas que façam valer seu projeto de dizer. A escolha do que dizer e da forma como fazê-lo é direcionada, entre outros aspectos, pela imagem que o produtor constrói do interlocutor, antes mesmo de interpelá-lo à interação, e pela expectativa de sua atitude responsiva (BAKHTIN, 2002, 2003).

O pressuposto de que a produção textual constitui uma atividade intersubjetiva orienta o conceito de negociação considerado neste estudo. Mediada por recursos linguísticos, a negociação é proposta pelo produtor tendo em consideração a atitude responsiva do interlocutor (BAKHTIN, 2002, 2003) e a intenção de direcionar a construção de sentido(s) e a interlocução conforme seus objetivos; no caso do artigo de opinião, tem como fim validar e fazer prevalecer o ponto de vista apresentado no texto.

O interesse por estratégias linguísticas mobilizadas em artigos de opinião direciona o olhar para o texto argumentativo stricto sensu (KOCH; FÁVERO, 1987, p. 9), no qual a argumentação é explicitada na superfície textual. A orientação argumentativa (ANSCOMBRE; DUCROT, 1976) pode ser apresentada de forma mais ou menos explícita, a depender do projeto de dizer envolvido em cada situação interlocutiva. Ou, nas palavras de Koch e Fávero (1987), num continuum argumentativo, podem-se localizar textos dotados de maior ou menor argumentatividade. $\mathrm{O}$ artigo de opinião pode ser tomado como um gênero representativo do polo em que figuram textos com maior grau de argumentatividade, o que pode ser considerado um de seus traços distintivos, já que é sustentado pela finalidade discursiva de manifestação de pontos de vista. Mesmo quando não se exprimem na superfície linguística marcas dêiticas do locutor (VION, 2004), explicitar as intenções faz parte das configurações desse gênero.

Tendo em conta a interação mediada por esse gênero, o texto argumentativo pode ser definido como um texto baseado em opinião no qual o produtor toma uma postura particular frente a um tema e tenta convencer o interlocutor a adotar tal posição (GOLDER; COIRIER, 1996). Argumentar, então, significa valer-se de estratégias linguísticas suficientes e adequadas para o êxito dos intentos do produtor (OSAKABE, 1977): modular a opinião do interlocutor conforme as representações da realidade expressas no texto.

Considerar o papel do interlocutor na dinâmica interativa implica o processo de negociação, que, no gênero aqui considerado, envolve a tentativa de levar o leitor a aceitar a orientação argumentativa proposta. A negociação, nesse contexto enunciativo, diz respeito à forma como o produtor do texto relaciona recursos linguísticos, manipulandoos para agir sobre o interlocutor, orientando a produção de sentido(s) a partir de sua posição sobre o tema abordado (GOLDER, 1996; GOLDER; COIRIER, 1994, 1996; PETRONI, 2005).

Assim, considera-se a ideia apresentada por Golder e Coirier (1996) de que a negociação pode ser medida principalmente pela presença de marcadores de endosso do 
falante (penso que, acredito que, dizem, acho que etc.), expressões de certeza/incerteza (certamente, provavelmente, talvez etc.) e formas axiológicas (é bom, é estúpido etc.), estas últimas não consideradas nas análises por serem pouco recorrentes no corpus. A essa lista, propõe-se acrescentar as marcas linguísticas que veiculam noções deônticas, que podem trazer nuances diversas, sendo consideradas, neste trabalho, as nocões de necessidade e sugestão (deve, pode etc.).

A análise de tais elementos como estratégia de negociação assenta-se na natureza interativa da linguagem e no papel ativo de ambos os interlocutores, o que implica considerar os elementos linguísticos não apenas como recurso de transmissão de informação, mas também como mecanismos de pressão e de persuasão sobre o outro, de quem se procura deter a atenção (PAULIUKONIS, 2003), sobre quem se tenta agir, direcionando-o para determinadas conclusões.

Embora se considere que diferentes recursos linguísticos (e mesmo paralinguísticos ou extralinguísticos) podem guiar a interlocução e demarcar a tentativa do produtor de estabelecer negociação com o interlocutor, a pesquisa parte do pressuposto de que os elementos modalizadores stricto sensu evidenciam os movimentos de negociação instaurados no texto.

\section{ALGUNS APONTAMENTOS SOBRE MODALIZAÇÃO E MODALIZADORES}

A proposta de analisar um corpus produzido numa situação real de interlocução a partir de uma perspectiva que não se limite às relações lógicas e sintáticas, mas que, além do significado da frase, considere a significação proposta no texto, para usar os termos de Dascal (1986), implica considerar o dictum como uma representação mais ou menos exteriorizada pelo relato do locutor (VION, 2004), e adotar a orientação de Parret (1988) de ultrapassar as definições e classificações das teorias gramaticais clássicas a respeito da modalidade. Parret (1988) assinala a necessidade de se promoverem estudos que considerem as modalidades não mais como propriedades de sequências lexicalizadas, mas como "verdadeiros atos de linguagem" (PARRET, 1988, p. 10), analisados a partir do contexto de ação de que tomam parte.

Seguindo essa perspectiva, considera-se que uma descrição mais completa da modalização deve compreender aspectos pragmáticos, o que significa tomá-la como um retrato da atitude do produtor do texto tanto em face do conteúdo proposicional quanto em face de seu interlocutor, conforme proposta de Parret (1988), Neves (2006) e Miranda (2005). Nessa perspectiva, os modalizadores podem ser descritos como estratégia linguístico-interlocutiva e, em conformidade com Parret (1988), como atos ilocutórios.

Os modalizadores são responsáveis, portanto, por demarcar a relação que o produtor do texto estabelece com o conteúdo do enunciado que produz e com o seu interlocutor. $\mathrm{O}$ produtor organiza seu texto em função de um querer dizer $(\mathrm{KOCH}, 2003 \mathrm{a})$ valendo-se de estratégias diversas que possam favorecer seu projeto de dizer. As escolhas linguísticas são motivadas "pelo jogo da produção e do reconhecimento das intenções" (PARRET, 1988, p. 80) movimentado via linguagem. 
A modalização pode ser atualizada no texto de forma mais ou menos explícita, mais ou menos velada, dependendo, entre outros fatores, do gênero textual ao qual o produtor recorre para levar a cabo suas intenções. Quanto mais alto é o grau de argumentação de um texto, mais passível ele está de ser preenchido por marcas de modalização explícita. Logo, o artigo de opinião constitui locus propício para o aparecimento dessa estratégia linguística, considerando que, nesse contexto enunciativo, a posição que o produtor toma em face do conteúdo que apresenta e de seu interlocutor é explicitada e assumida.

Neste estudo, são considerados os elementos modalizadores stricto sensu. Entendese que a função interpessoal é enfatizada quando se tem um enunciado marcadamente modalizado, conforme Neves (2006), o que se daria pela presença mais evidente do falante e do interlocutor, segundo a autora. Tendo em conta o corpus analisado, são observados os eixos tradicionalmente considerados no campo da Linguística: modalização epistêmica e deôntica.

O eixo epistêmico se refere ao eixo da crença, reportando o conhecimento do produtor do texto sobre o tema de referência (NEVES, 1996; CASTILHO; CASTILHO, 1992). Pode ser manifestado pela necessidade epistêmica ou pela possibilidade epistêmica. A primeira é expressa no corpus pelos seguintes expedientes linguísticos: obviamente, certamente, com certeza, é com clareza que, sem dúvidas, é claro que, está garantido que, sabe-se de, sabemos que, tenho certeza (de que). A segunda é expressa predominantemente por meio do verbo poder e, em menor medida, pelo verbo dever, conjugados, e pelas expressões talvez, provavelmente, o possível, é provável que, quem sabe, mais provável.

De maneira geral, nos estudos linguísticos, o eixo deôntico é relacionado à conduta, situado no domínio do dever (NEVES, 1996). Conforme Castilho e Castilho (1992), indica que o falante considera o conteúdo proposicional como um estado de coisas que deve, precisa ocorrer obrigatoriamente.

Tendo em vista as nuances da modalização deôntica identificadas no corpus, propõe-se reconfigurar a descrição citada no parágrafo acima de modo a conformá-la ao gênero aqui investigado e à intenção de observar os atos ilocutórios mobilizados. Assim, entende-se que a modalização deôntica, que pertence ao eixo da conduta e se situa no domínio do dever, quando figurando em artigos de opinião, apresenta duas nuances:

i. necessidade: relacionada à noção de necessidade/obrigação, retrata um ato de asserção forte (BORILLO, 1982), que indica que o produtor se compromete com o conteúdo do texto ao apresentá-lo como uma necessidade, orientando uma leitura incisiva sobre a realidade. No corpus analisado, a necessidade deôntica é expressa por meio dos verbos precisar, dever e poder (este antecedido de advérbio de negação - não pode) conjugados, pelas expressões ter que/de conjugada, é preciso (que), é necessário (que), obrigatoriamente e, ainda, pela expressão nominal nossa obrigação;

ii. possibilidade: relacionada à noção de sugestão, retrata um ato de asserção fraca (BORILLO, 1982), que indica que o produtor não se compromete integralmente com o conteúdo do texto ao apresentá-lo como uma possibilidade, orientando uma leitura menos incisiva sobre a realidade. No corpus investigado, é expressa preponderantemente por meio do verbo poder e do verbo dever conjugados no futuro do pretérito e, de forma menos recorrente, pelo verbo precisar conjugado no futuro do pretérito e pelas expressões 
uma sugestão e é possível, além de constar uma ocorrência da expressão ter que. Em relação a esta, cabe ressalvar que, apesar de ser uma expressão prototípica da necessidade deôntica, no ambiente cotextual em que figura, acaba tomando ares de sugestão.

Quando se recorre à possibilidade e à necessidade, epistêmica ou deôntica, atualizase o ato ilocutório de asserção forte e de asserção fraca (BORILLO, 1982), respectivamente. Ambas as estratégias são postas em cena com vista a alinhar o leitor à orientação argumentativa dada no texto. Portanto, podem ser tomadas como produtivas na composição do artigo de opinião.

\section{NEGOCIAÇÃO ENFÁTICA E NEGOCIAÇÃO ATENUADA}

Tendo em foco o papel dos elementos modalizadores, observa-se no corpus tentativas de dois macromovimentos de negociação, que foram descritos a partir da proposição de duas categorias: negociação enfática e negociação atenuada. Esses dois movimentos podem ser analisados em termos da força ilocutória dos modalizadores, conforme enunciado anteriormente: atos de asserção fraca e atos de asserção forte (BORILLO, 1982), respectivamente. Tais atos estão relacionados ao tipo de modalizador mobilizado no texto: possibilidade epistêmica e deôntica e necessidade epistêmica e deôntica, respectivamente. O esquema abaixo sumariza a relação entre as categorias propostas, força ilocutória e tipos de modalizadores.

\section{Esquema 1 - Força ilocutória e modalizadores}

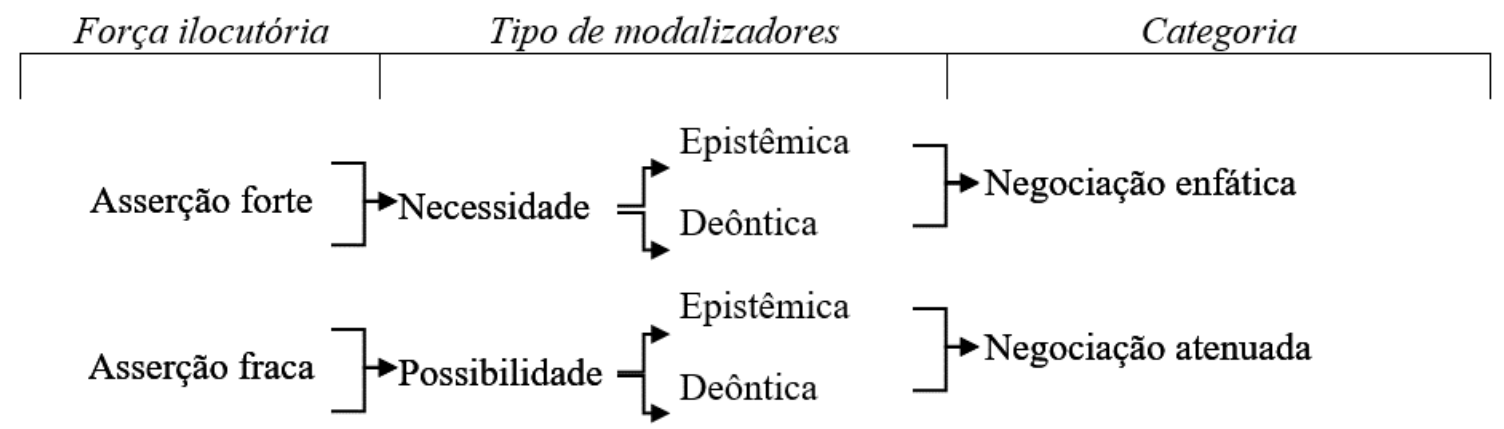

A descrição apresentada por Hengeveld (1989) em relação a operadores de ilocução contribui para explicar as categorias propostas. O autor relaciona tais operadores aos possíveis efeitos perlocucionários de um ato de fala, em contraponto com os operadores de proposição, que dizem respeito ao conteúdo do texto. Para o autor, os operadores de ilocução estão relacionados à intenção comunicativa que leva o produtor a apresentar tal conteúdo, relacionando-os às estratégias de mitigação e reforço, que são traduzidas por Camparini (2009) como atenuação e asseveração, respectivamente. Da orientação de Hengeveld (1989), toma-se principalmente a descrição da função geral das estratégias em questão: reforçar ou atenuar o ato de fala sobre o interlocutor. 
Os elementos modalizadores que retratam tentativas de negociação enfática são responsáveis por explicitar um produtor que se relaciona com o seu texto a partir de um engajamento total com o conteúdo modalizado, conforme se observa no parágrafo a seguir, que congrega tentativas de negociação enfática mediada pela necessidade epistêmica e pela necessidade deôntica, respectivamente:

[01] E claro que precisamos manter a Maquina de Chuva ligada, a Amazônia precisa dela para não virar cerrado, também pessoas, o Brasil e países vizinhos precisam das chuvas porque a maioria da América do Sul é sustentada pela Maquina de Chuva, sendo assim que ela permaneça ligada para manter o clima equilibrado da região Sul, mantendo também as hidrelétricas que mantem as energias que precisamos para manter nosso aparelhos eletrônicos, manter a agricultura, pois é nosso alimento, entre varias outras coisas essenciais para nos como Agua para beber. (Necessidade epistêmica, Necessidade deôntica) ${ }^{3}$

Vê-se, nesse parágrafo, que a modalização epistêmica tem como escopo o enunciado deonticamente modalizado. O elemento deôntico (precisamos), em si, demarca um caráter incisivo, impositivo. $\mathrm{O}$ fato de o produtor recorrer ainda a um expediente do campo da necessidade epistêmica (É claro que) reforça o tom de asserção forte do enunciado e apresenta uma forma de constatar a necessidade. Nesse caso, pode-se aplicar a interpretação proposta por Camparini (2009): "a análise da sobremodalização permite que se verifique como a indicação de certeza/incerteza do falante interfere na percepção da força com que a obrigação, permissão ou autorização foi instaurada" (CAMPARINI, 2009, p. 192).

Com essa estratégia, o produtor se posiciona como alguém que tem conhecimento e autoridade sobre o conteúdo tratado no texto, o que afiança a tentativa de agir incisivamente sobre o interlocutor ao apresentar certa leitura do mundo como necessária, buscando minimizar as chances do parceiro da interlocução de contra-argumentar. A opinião é posta de tal forma que negá-la seria admitir-se ignorante sobre os fatos trazidos para o texto. Nesse caso, explicitar a situação atual do problema em debate é dado como um primeiro passo para chegar à proposição de ações que minimizem o quadro apresentado. Parece que o produtor procura primeiro se achegar ao leitor, angariando sua confiança e concordância, para depois pontuar a tese que vai defender no texto, estratégia que pode viabilizar uma negociação exitosa.

Para tanto, o produtor busca assegurar que a leitura aí proposta, ou mesmo imposta, seja aceita pelo interlocutor. Observa-se que, nesse caso, o tom incisivo explicitado pelos modalizadores é sustentado por outros elementos do cotexto linguístico. Citam-se o uso predominante do presente do indicativo e o uso de verbo no modo imperativo como estratégias que contribuem para sustentar o processo de negociação enfática. Nesse sentido, embora os modalizadores sejam considerados como tendo função de explicitar o ato ilocutório de asserção, tornando o ato de fala mais forte, considera-se que o cotexto toma também parte nesse processo.

\footnotetext{
${ }^{3}$ Os parágrafos que constituem o corpus são transcrições ipsis litteris dos textos coletados.
} 
Se, por um lado, pode-se tentar agir sobre a opinião do interlocutor por meio de uma ação mais incisiva, como é o caso da negociação enfática, por outro, também constitui estratégia válida para a argumentação certo distanciamento do produtor em relação ao seu próprio texto, numa negociação atenuada.

Os modalizadores alocados nessa categoria explicitam certo distanciamento do produtor em relação ao seu próprio texto e abrandam o ato de fala. Diferente do que ocorre com o processo de negociação enfática, na categoria em tela, o produtor apresenta argumentos não de forma incisiva, mas como uma sugestão de leitura de fatos do mundo, conforme ilustram os parágrafos a seguir:

\begin{abstract}
[02] Se os governantes fizessem a sua parte, certamente haveria maior fiscalização, tendo maior fiscalização, a nossa Amazônia não estaria sofrendo. Mas não depende somente dos governantes para acabar com o desmatamento, e sim de toda a humanidade, pois as pessoas que morram na Amazônia podem prezervar-la, e os que não morram podem ajudar de forma indireta, como por exemplo comprar apenas madeira legalizada. (Possibilidade deôntica)
\end{abstract}

[03] Ele também explica como a chuva, ventos, oceanos e florestas estão interligados e por que alteram esse equilíbrio pode trazer danos irreversíveis a vida e conclui o problema não é a natureza é o humano. (Possibilidade epistêmica)

Em ambos os casos, o produtor não se compromete com o conteúdo do texto e busca propor uma interação pautada em sugestões de leituras em relação ao tema trazido para debate. Em [02], vê-se um produtor que procura se posicionar como cidadão consciente e propor soluções para o problema abordado. Observa-se que, ao recorrer à asserção fraca, tenta se apresentar como um analista ponderado, que é capaz de interpretar criticamente o mundo, mas que não quer ser incisivo com o interlocutor. Ao contrário, procura se aproximar deste a partir de uma interação menos tensa, buscando pontuar soluções possíveis para o problema trazido para debate.

O modalizador do parágrafo [03] permite que o comprometimento do produtor em relação ao conteúdo da mensagem se dê de forma "frouxa", uma vez que se promove uma "relativização" da certeza, conforme termo usado por Neves (2006, p. 174). Para a autora, ao situar seu enunciado no campo graduável do possível, o produtor confessa suas dúvidas e incertezas e, com isso, ganha em credibilidade. Em casos como o ilustrado nesse parágrafo, é recorrente no corpus a estratégia de amparar o conteúdo modalizado na voz da ciência para dotar o enunciado de força argumentativa, na medida em que tal estratégia apresenta-se como um argumento de autoridade, embora nem sempre se explicite a polifonia. Como mesmo a ciência, que está avalizada por técnicas e procedimentos que permitem uma previsão relativamente precisa de fatos futuros, não arrisca uma avaliação incisiva nesses casos, também o produtor se exime da responsabilidade pelo conteúdo modalizado, alçando-o à esfera do possível. Mais do que não se comprometer com o conteúdo expresso, e, com isso, ganhar em credibilidade com o leitor, o produtor garante um espaço propício para a imposição de ações necessárias com vista a impedir que a previsão se torne realidade, o que não poderia fazer se as consequências fossem postas como certas, inevitáveis, pois, nesse caso, qualquer proposta de ação seria improdutiva. 
A observação de tentativas dos dois movimentos de negociação, enfática e atenuada, reitera a ideia de que os elementos modalizadores, entre outras coisas, "revelam o maior ou menor grau de engajamento do falante com relação ao conteúdo proposicional veiculado, apontam as conclusões para as quais os diversos enunciados podem servir de argumento" (KOCH, 2002, p. 136) e determinam "o grau de tensão que se estabelece entre os interlocutores" (KOCH, 2002, p. 86), delineando o tipo de interação pretendida pelo produtor.

Ao recorrer a modalizadores, na "configuração linguística da realidade" (PAULIUKONIS, 2000, p. 91) que propõem no texto, os produtores ora procuram impor um ponto de vista, interpelando o interlocutor a tomar como certa a análise apresentada no texto, ora buscam se aproximar do leitor de modo a fazer dele um cúmplice, parceiro na construção da realidade que propõe via linguagem. Observa-se que os modalizadores pertencentes a ambos os eixos, epistêmico e deôntico, são postos em cena no artigo de opinião no intuito de orientar uma atitude responsiva imediata: a adesão do interlocutor ao discurso, a aceitação deste pelo parceiro da interação.

A negociação enfática se configura como uma estratégia de interpelação (RODRIGUES, 2001), pois o produtor - avalizado por um suposto conhecimento que tem dos fatos abordados no texto, ainda que tal conhecimento seja discursivamente criado, e pela assunção de uma suposta autoridade que lhe consente asseverar e impor uma interpretação acerca do tema trazido para debate - impõe ao leitor um determinado ponto de vista, que é apresentado como uma verdade à qual o leitor deve se sentir compelido, persuadido a aderir.

Atualizada pela necessidade epistêmica ou deôntica, a asserção forte contribui para o processo de negociação na medida em que sustenta a construção da imagem de um produtor que se engaja com seu texto e revela suas intenções de agir sobre o outro, promovendo, assim, um ambiente propício para a orientação declarada de pontos de vista. Ao assumir total responsabilidade em relação ao conteúdo apresentado, o produtor cria também para o interlocutor o "dever de crer", conforme analisa Koch (2002). Segundo a autora, decorre daí um discurso autoritário, não admitindo contestação: “se, por acaso, o alocutário puser em dúvida o conteúdo da asserção, o locutor, provavelmente, dirá algo como: 'Pois se eu estou lhe dizendo...'. Rejeitar a asserção, nesse caso, será rejeitar a própria continuidade do discurso" (KOCH, 2002, p. 138).

O tom imperativo implica uma posição de autoridade de quem escreve não apenas em relação ao conteúdo do texto, mas também em relação ao interlocutor, que é interpelado a aceitar a orientação argumentativa proposta. Com isso, cria-se uma interlocução com um alto grau de tensão, que é demarcada pelo relacionamento que o produtor propõe tanto com o enunciado quanto com o interlocutor, expondo sua face e também a do interlocutor, uma vez que exige deste um posicionamento. Aceitar ou negar a "verdade" apresentada no texto significa um exercício responsivo que precisa ser assumido pelo parceiro da interação. 
O alto grau de engajamento e a tensão relacionados ao uso da asserção forte representam um risco ao produtor, que se expõe à contra-argumentação. Considerando o papel ativo do leitor no processo de negociação, entende-se que a rejeição é possível, o que permite dizer que recorrer a elementos do polo da necessidade implica tanto uma orientação mais incisiva do modo de perceber o mundo quanto a possibilidade de descontinuação do diálogo, pois uma recusa, por parte do interlocutor, da leitura apresentada no texto pode pôr abaixo o debate pretendido. Trata-se, pois, de um passo arriscado para o aluno, uma vez que este, de forma geral, não domina a temática e a situação de interação na mesma medida que o articulista o faz, conforme discutido anteriormente.

Por sua vez, os elementos modalizadores que explicitam movimentos de negociação atenuada retratam o ato ilocutório de asserção fraca, atualizado por meio de modalizadores da possibilidade epistêmica ou deôntica. Ao recorrer a essa estratégia, "o locutor não impõe (ou finge não impor) a sua opinião, ainda que se trate de mera manobra discursiva, deixando (ou fingindo deixar), assim, ao alocutário a possibilidade de aceitar ou não os argumentos apresentados, de aderir ou não ao discurso que lhe é dirigido" (KOCH, 2002, p. 86).

Nessa perspectiva, os modalizadores contribuem para a negociação na medida em que abrem espaço à crítica alheia e, dessa forma, promove-se uma aproximação entre produtor e leitor, num processo de agenciamento da negociação.

Essa estratégia permite ao produtor não se engajar totalmente com o conteúdo de seu texto, uma vez que não se responsabiliza integralmente pelo dito, propondo uma relação menos tensa com o texto e também com o interlocutor, promovendo, assim, um ambiente mais propício à preservação de sua face e a de seu parceiro.

Nesse processo, as possibilidades de continuidade do diálogo são, pois, maximizadas na medida em que, frente a uma possível recusa do conteúdo modalizado, o produtor pode se defender dizendo tratar-se de uma leitura possível, mas não necessária, do mundo. Propõe-se, assim, uma imagem positiva do produtor, a partir de sua apresentação como um analista capaz de admitir a limitação de seus conhecimentos e de acolher possíveis contra-argumentos.

\section{AINDA ALGUMAS CONSIDERAÇÕES}

A categorização proposta esteve orientada, basicamente, por fatores pragmáticos, o que permitiu congregar em ambas as categorias elementos da necessidade epistêmica e deôntica. No entanto, é preciso considerar, como lembra Paulillo (1987), que as modalidades têm "um estatuto essencialmente semântico (que provém de sua origem na Lógica)" (PAULILLO, 1987, p. 5). Assim, sem desconsiderar as particularidades semânticas dos eixos deôntico e epistêmico, entendeu-se pertinente, no nível discursivopragmático, aproximá-los tendo em mente o relacionamento que o produtor mantém com o texto e com o interlocutor e o projeto de dizer que orienta tal relacionamento. 
Na consideração da modalização no nível interacional, que não se limita a uma análise sintático-semântica de expedientes linguísticos, ficam em evidência os atos de fala indiretos. Pode-se recorrer ao eixo deôntico não para orientar ações, mas para agir sobre o interlocutor no sentido de convencê-lo da validade da tese apresentada, conforme visualizado no corpus. Em outras situações de interação, a modalização epistêmica pode ser usada para orientar ações. Como lembra Koch (2003b), nas situações concretas de interação, é o contexto em que o enunciado foi produzido que permitirá fixar sua força ilocutória.

Assim, a abordagem da modalização só passa a ter sentido se esta for analisada no contexto enunciativo de onde emerge, uma vez que, conforme analisa Coracini (1991), as modalidades constituem verdadeiras estratégias discursivas, e, portanto, não podem ser isoladas do ato de fala em que estão inseridas. Nessa perspectiva, considera-se a relevância de estudar a atuação das modalidades em contextos específicos, observando os movimentos discursivo-pragmáticos propostos em situações particulares de interação, como é o caso do texto argumentativo escrito.

Assim, a pesquisa se propõe a apresentar contribuições aos estudos na área da Linguística por pontuar o papel pragmático-interativo dos modalizadores, considerando o nível interacional, questão pouco debatida na literatura atual, que, em geral, centra a atenção no relacionamento do produtor com o enunciado que produz. Espera-se ter contribuído para diminuir a lacuna, citada por Miranda (2005), em termos de procedimentos analíticos capazes de captar o papel dos recursos modalizadores no "monitoramento da dinâmica dos papéis sociais, ou seja, da dinâmica de sujeitos comunicativos operando sobre outros, ou de sujeitos comunicativos operando sobre si mesmos." (MIRANDA, 2005, p. 181).

Ressalta-se, uma vez mais, que, embora o foco central deste trabalho seja os modalizadores, observa-se ser fundamental no desenvolvimento do processo de negociação o papel do cotexto, de modo a reforçar a necessidade de considerar os elementos modalizadores em seu cotexto linguístico. Observando tanto os modalizadores - e sua forma de lexicalização, aspecto que não foi abordado neste artigo - quanto seu entorno linguístico, verifica-se que há um continuum que vai do extremo da negociação enfática ao extremo na negociação atenuada. No entremeio, estão diversos pontos a partir dos quais o produtor escolhe enunciar, cujo limite não é facilmente estabelecido, uma vez que são congregadas estratégias diversas, muitas vezes apontando para direções opostas, que dificultam uma gradação clara entre um e outro ponto. Apesar de os diversos pontos do continuum a que chega o enunciado não ter sido foco de análise da pesquisa proposta, a constatação da recorrência de tal deslize parece significativa para uma análise que considere a interação, pois mostra como o produtor lida com as possibilidades múltiplas que encontra na língua para fazer vingar seu projeto de dizer.

Este estudo aponta resultados que podem ser significativos para encaminhamentos relativos à produção do texto argumentativo e, especificamente, à modalização linguística, uma vez que os usos efetivos que os alunos fazem da língua parecem constituir dado relevante para a organização do trabalho pedagógico com vista à superação de dificuldades de interação mediada pela modalidade escrita. Além disso, as categorias propostas podem ser didaticamente exploradas. Nesse sentido, as análises aqui postas visam a contribuir, conforme Leal (2008), para "entender os processos de escrita, o funcionamento de um texto escrito, para poder ensinar" (LEAL, 2008, p. 54). 
Em outros termos, entende-se, conforme Leal (2008), que a intenção de promover uma interação pedagogicamente relevante deve considerar os textos produzidos pelos alunos como instâncias discursivas que são atravessadas por um conjunto de fatores ou de determinantes. E "saber detectar nos textos as marcas desses determinantes é poder começar a perceber a palavra do "outro' (do 'aprendiz"), para poder realizar a atitude responsiva ativa" (LEAL, 2008, p. 56).

Ressalta-se a importância de possibilitar ao aluno o reconhecimento e a análise das marcas linguísticas da modalização (como também de outras categorias, como o posto, o pressuposto, o subentendido etc.), um caminho necessário para se chegar a uma intelecção mais aprofundada do texto $(\mathrm{KOCH}, 2002)$, por um lado, e a uma produção mais adequada aos contextos enunciativos de onde emergem textos com alto grau de argumentação, por outro. A abordagem da modalização linguística em sala de aula visa a auxiliar os alunos a lidarem com o texto, seja como leitores, que precisam alcançar as diversas "camadas" de significação (DASCAL, 1986) presentes em cada texto, seja como produtores, que precisam saber usar os recursos linguísticos de que a língua dispõe para alcançar os objetivos esperados em cada interação. A modalização linguística é relevante para o exercício da leitura e da produção escrita, uma vez que essa categoria está diretamente ligada à intencionalidade do produtor, ao seu grau de engajamento com relação aos enunciados que produz e ao relacionamento que pretende instaurar com o interlocutor, ou, ainda, à "maneira como representa a si mesmo, ao outro e ao mundo por meio da linguagem" (KOCH, 2002, p. 160).

Os parágrafos dos textos produzidos pelos alunos revelam que se faz necessário um trabalho mais aprofundado tanto com a modalização quanto com a argumentação stricto sensu e com o gênero em que tal argumentação é posta em cena que possa tornar o aluno mais consciente das possibilidades de orientação de sentido(s) viabilizadas pelos modalizadores. O uso consciente e produtivo das estratégias modalizadoras depende também das habilidades do aluno de lidar com aspectos textuais que vão além do domínio dos elementos modalizadores, implicando, por exemplo, o domínio das relações de coesão e coerência e da estrutura da oração, para citar apenas alguns dos aspectos que precisam ser considerados na construção do texto argumentativo escrito, e, de forma mais ampla, o domínio da situação de interação. Tais aspectos são relevantes para que as "tentativas" de negociação, apontadas neste trabalho, possam passar à condição de estratégias exitosas de negociação.

\section{REFERÊNCIAS}

ANSCOMBRE, J.-C.; DUCROT, O. L'argumentation dans la langue. Langages, $10^{\mathrm{e}}$ année, n. 42, p. 5-27, 1976.

BAKHTIN, M. Os gêneros do discurso. In: Bezerra. 4. ed. São Paulo: Martins Fontes, 2003. p. 261-306.

Estética da criação verbal. Tradução de Paulo ; [N. V. Volochinov]. Marxismo e filosofia da linguagem. Tradução de Michel Lahud e Yara Frateschi Vieira. 10. ed. São Paulo: Annablume; Hucitec, 2002.

BESSA NEVES, J. S. Estudo semântico-enunciativo da modalidade em artigos de opinião. 2006. Tese (Doutorado) - Departamento de Letras, Pontifícia Universidade Católica do Rio de Janeiro, Rio de Janeiro.

BORILLO, A. Deux aspects de la modalité assertive: croire et savoir. Langages, $16^{\mathrm{e}}$ année, n. 67, p. 33 $53,1982$. 
CAMPARINI, A. M. P. A modalização deôntica no discurso jurídico. In: PEZATTI, E. G. (Org.). Pesquisas em gramática funcional: descrição do português. São Paulo: EDUNESP, 2009. p. 173-202. CASTILHO, A. T.; CASTILHO, C. Advérbios modalizadores. In: ILARI, R. (Org.). Gramática do português falado. Campinas: UNICAMP; FAPESP, 1992. v. 2. p. 213-261.

CORACINI, M. J. R. F. Um fazer persuasivo: o discurso subjetivo da ciência. São Paulo: EDUC; Campinas: Pontes, 1991.

CORBARI, A. T. Elementos modalizadores como estratégia de negociação em textos opinativos produzidos por alunos de Ensino Médio. 2013. 220f. Tese (Doutorado em Letras e Linguística) Programa de Pós-Graduação em Letras e Linguística, Universidade Federal da Bahia, Salvador, 2013.

. Um estudo sobre os processos de modalização estabelecidos pelo par "é + adjetivo" em artigos de opinião publicados no jornal Observatório da Imprensa. 2008. Dissertação (Mestrado) - Programa de Pós-Graduação stricto sensu em Letras, Universidade Estadual do Oeste do Paraná, Cascavel, 2008.

DASCAL, M. A relevância do mal-entendido. Cadernos de Estudos Lingüísticos, Campinas, n. 11, p.199217, jul./dez. 1986.

DUCROT, O. O dizer e o dito. Tradução de Eduardo Guimarães. Campinas: Pontes, 1987.

GOLDER, C. La production de discours argumentatifs: revue de questions. Revue française de pédagogie, Paris, v. 116, p. 119-134, 1996.

; COIRIER, P. The production and recognition of typological argumentative text markers.

Argumentation, Dordrecht-Boston, v. 10, p. 271-282, 1996. v. 18 , p. 187-210, 1994.

Argumentative text writing: developmental trends. Discourse Processes, Philadelphia,

HENGEVELD, K. Layers and operatores in Functional Grammar. Journal of Linguistics, v. 25, p. $127-$ $157,1989$.

KOCH, I. G. V. Desvendado os segredos do texto. 2. ed. São Paulo: Cortez, 2003a. A inter-ação pela linguagem. 8. ed. rev. e ampl. São Paulo: Contexto, 2003b. Argumentação e linguagem. 8. ed. São Paulo: Cortez, 2002.

\section{7.} ; FÁVERO, Leonor. Contribuição a uma tipologia textual. Letras \& Letras, v. 3, n. 1, p. 3-10,

LEAL, L. F. V. A formação do produtor de texto escrito na escola: uma análise das relações entre os processos interlocutivos e os processos de ensino. In: COSTA VAL, M. G.; ROCHA, G. (Org.).

Reflexões sobre práticas escolares de produção de texto: o sujeito-autor. Belo Horizonte: Autêntica; CEALE; FaE; UFMG, 2008. p. 53-67.

MARCUSCHI, L. A. Produção textual, análise de gêneros e compreensão. São Paulo: Parábola, 2008.

MIRANDA, N. S. Modalidade: o gerenciamento da interação. In: Linguística e cognição. Juiz de Fora: UFJF, 2005. p. 171-195. ; NAME, M. C. (Org.).

MORAES, R. Uma tempestade de luz: a compreensão possibilitada pela análise textual discursiva. Ciência \& Educação, Bauru, v. 9, n. 2, p. 191-211, 2003.

; GALIAZZI, M. C. Análise textual discursiva. Ijuí: UNIJUÍ, 2007.

Análise textual discursiva: processo reconstrutivo de múltiplas faces. Ciência \& Educação, Bauru, v. 12, n. 1, p. 117-128, 2006.

MOREIRA, H.; CALEFFE, L. G. Metodologia da pesquisa para o professor pesquisador. 2. ed. Rio de Janeiro: Lamparina, 2008.

NEVES, M. H. M. Texto e gramática. São Paulo: Contexto, 2006.

Gramática de usos do português. São Paulo: EDUNESP, 2000.

. A modalidade: In: KOCH, I. V. (Org.). Gramática do português falado. São Paulo: UNICAMP; FAPESP, 1996. v. 6. p. 163-195.

OSAKABE, H. Redações no vestibular: provas de argumentação. Cadernos de Pesquisa, São Paulo, n. 23, p. 51-59, dez. 1977. Disponível em: <http://educa.fcc.org.br/scielo.

php?script=sci_arttext\&pid=S0100-15741977000400006\& lng=pt\&nrm=iso $>$. Acesso em: 15 abr. 2011. PARRET, H. Enunciação e pragmática. Tradução de Eni Pulcinelli Orlandi et al. Campinas: UNICAMP, 1988.

PAULILLO, R. Modalidade e asserção: um estudo semântico-pragmático de enunciados de possibilidade epistêmica. 1987. Dissertação (Mestrado em Linguística) - Departamento de Linguística do Instituto de Estudos da Linguagem, Universidade Estadual de Campinas, Campinas. 
PAULIUKONIS, M. A. L. Progressão textual e modalização. Cadernos do CNLF, Rio de Janeiro, série 7, n. 7, 2003. Disponível em: <http://www.filologia.org.br/viicnlf/anais/ caderno07-17.html>. Acesso em: 05 mar. 2011.

Processos de discursivização: da língua ao discurso: caracterizações genéricas e específicas do texto argumentativo. Veredas: Revista de Estudos Lingüísticos, Juiz de Fora, v. 4, n. 2, p. 89-96, 2000. PETRONI, M. R. Construção do objeto discutível: argumentação e interação. Polifonia, Cuiabá, n. 10, p. 113-133, 2005.

ROCHA, G. O papel da revisão na apropriação de habilidades textuais pela criança. In: COSTA VAL, M. G.; ROCHA, G. (Org.). Reflexões sobre práticas escolares de produção de texto: o sujeito-autor. Belo Horizonte: Autêntica; CEALE; FaE; UFMG, 2008. p. 69-83.

RODRIGUES, R. H. A constituição e o funcionamento do gênero jornalístico artigo: cronotopo e dialogismo. 2001. Tese (Doutorado em Lingüística Aplicada e Estudos da Linguagem) - Pontifícia Universidade Católica de São Paulo, São Paulo, 2001. Disponível em:

<http://www.pucsp.br/pos/lael/lael-inf/def_teses. html>. Acesso em: 04 mar. 2007.

VION, R. Modalisation, dialogisme et polyphonie. 2005. Disponível em : <http://www.dialogicidad.cl/papers/Vion.pdf>. Acesso em: 05 jun. 2011.

Modalités, modalisations et discours representes. Langages, 38 année, n. 156, p. 96-110, 2004.

Recebido em: 27/10/15. Aprovado em : 24/02/16.

Title: Modal operators: negotiation in opinion piece

Author: Alcione Tereza Corbari

Abstract: This paper aims to present partial research findings of a doctoral thesis on the use of linguistic modality strategies. The investigation considers the role of modal operators in the negotiation process established by the relationship of the text producer with both the text content and the interlocutor. The analysis focuses on epistemic and deontic modal operators in paragraphs of opinion pieces written by 3 rd year secondary students from a public school in Cascavel (Paraná, Brazil). This research is qualitative-oriented, using procedures of qualitative content analysis, following a descriptive-interpretive approach. The study is based on theoretical framework that focuses on analyzing real texts and examining specific linguistic resources, given the enunciation conditions involved in text production. It was found that students use strategies to mark their relationship with their own text and their interlocutor that fall in two negotiation categories: emphatic negotiation and attenuated negotiation, which involves illocutionary acts of strong and weak assertion, respectively.

Keywords: Modal operator. Negotiation. Opinion piece. Secondary Education.

Título: Modelizadores: la negociación en artículo de opinión

Autor: Alcione Tereza Corbari

Resumen: Este artículo presenta resultados parciales de tesis para doctorado que tuvo por objetivo investigar el uso de estrategias de modelización lingüística, considerando el rol de los modelizadores en el proceso de negociación demarcada por el relacionamiento que el productor establece con el contenido del texto y con o interlocutor. Se toman para análisis modelizadores de los ejes epistémico y deóntico ambientados en párrafos de artículos de opinión producidos por alumnos del $3^{\circ}$ año de la Escuela Secundaria de una escuela pública de Cascavel/PR. La investigación cualitativa adopta cómo procedimiento metodológico el análisis textual cualitativo, y considera una perspectiva descriptivo-interpretativa. El estudio se apoya en supuestos teóricos que preconizan el análisis de textos reales y que permiten considerar expedientes lingüísticos específicos, teniendo en cuenta las condiciones enunciativas involucradas en la producción del texto. Fue observado que los alumnos recuren a estrategias de relacionamiento frente al propio texto y al interlocutor, que fueran congregados en dos categorías: negociación enfática y negociación atenuada, que involucran respectivamente los actos no locutorios de aserción fuerte y de aserción flaca.

Palabras-clave: Modelizador. Negociación. Artículo de Opinión. Enseñanza Secundaria. 